\title{
Genetic stability of Campylobacter coli in patients with primary antibody deficiencies
}

Cinzia Milito, MD, PhD

Isabella Quinti, MD, $\mathrm{PhD}^{*}$

isabella.quinti@uniroma1.it

Department of Molecular Medicine, Sapienza University of Rome, Rome, Italy

${ }^{*}$ Corresponding author: Isabella Quinti, MD, PhD, Department of Molecular Medicine, Sapienza University of Rome, Viale dell'Università 37, 00185, Rome, Italy.

No funding was received for this work.

Conflicts of interest: The authors declare that they have no relevant conflicts of interest.

To the Editor:

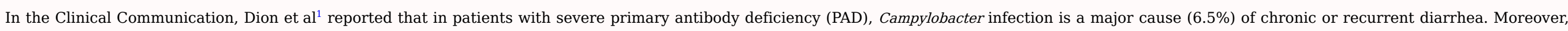

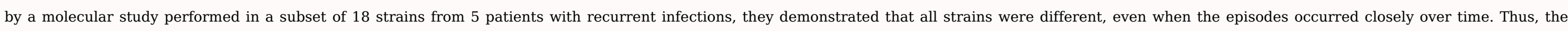
authors hypothesized that reinfection would be more likely than persistent colonization, although colonization with multiple strains cannot be excluded.

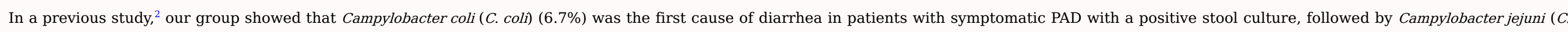

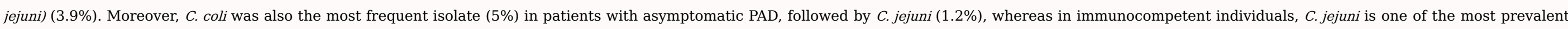
etiologic agents of gastroenteritis and C. coli has a low prevalence in diarrheal disease. ${ }^{3,4}$

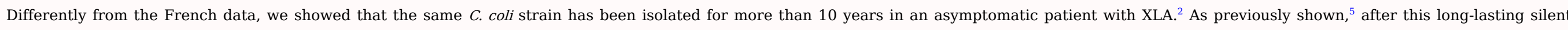

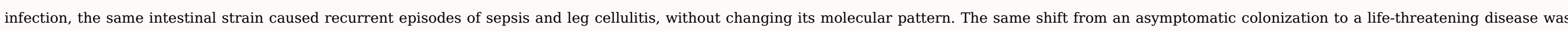

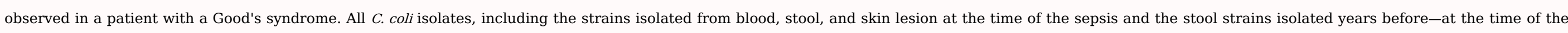

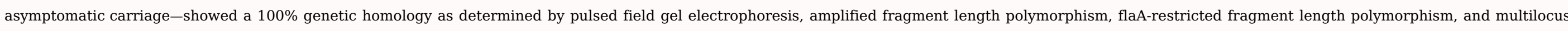
sequence typing.

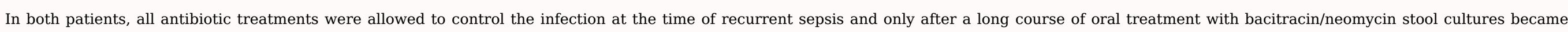
persistently negative and there was no disease recurrence.

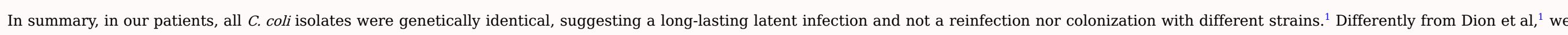

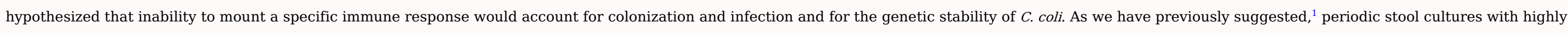
sensitive techniques should be performed in PAD.

\section{References}

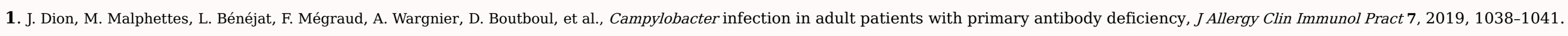

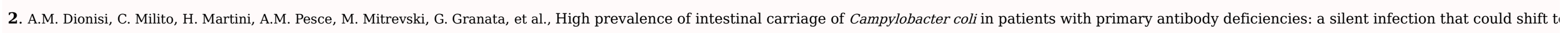
a life-threatening condition, J Clin Gastroenterol 45, 2011, 474-475.

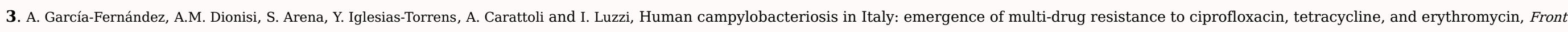
Microbiol 9, 2018, 1906. 
4. I. Melamed, Y. Bujanover, Y.S. Igra, D. Schwartz, V. Zakuth and Z. Spirer, Campylobacter enteritis in normal and immunodeficient patient, Am J Dis Child 137, $1983,752-753$.

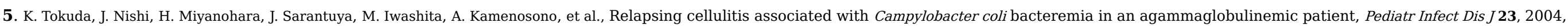
$577-579$.

\section{Queries and Answers}

Query: If there are any drug dosages in your article, please verify them and indicate that you have done so by initialing this query

Answer: In the article, there are not drug dosages.

Query: Please confirm that the funding and conflicts of interest statements are both complete and accurate.

Answer: Funding and conflicts of interests are both complete and accurate.

\section{Query: Please spell out XLA.}

Answer: X-linked Agammaglobulinemia (XLA)

Query: Please verify the year for reference 1.

Answer: The year of reference 1 is 2019.

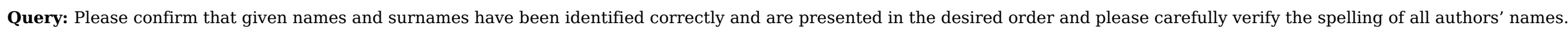
Answer: Given names and surnames are correct and presented in the desidered order. The spelling of authors' names is correct. 